Endot oxi $n$ tol er ance i $n$ human i nt $r$ ahepat i c bi I i ary epi thel i al cel I s is i nduced by upr egul at $i$ on of I RAK M

\begin{tabular}{|l|l|}
\hline 著者 & $\begin{array}{l}\text { Har ada Keni chi , I sse Kum ko, Sat o Yasunor i , } \\
\text { Ozaki Sat or u, Nakanuma Yasuni }\end{array}$ \\
\hline $\begin{array}{l}\text { j our nal or } \\
\text { publ i cat i on t i t l e }\end{array}$ & Li ver I nt er nat i onal \\
\hline Vol une & 26 \\
\hline number & 8 \\
\hline page r ange & $935-942$ \\
\hline year & $2006-10-01$ \\
\hline URL & ht t p: //hdl . handl e. net /2297/7543 \\
\hline
\end{tabular}




\section{- Title Page -}

Endotoxin tolerance in human intrahepatic biliary epithelial cells is induced by up-regulation of IRAK-M

Kenichi Harada, Kumiko Isse, Yasunori Sato, Satoru Ozaki, and Yasuni Nakanuma

Department of Human Pathology, Kanazawa University Graduate School of Medicine, Kanazawa, Japan

Short title: Endotoxin tolerance in biliary cells

Financial Support: This work was supported by grant No.16790205 from the Japanese Ministry of Education, Culture, Sports, Science and Technology and Kurozumi Medical Foundation

Address correspondence to: Yasuni Nakanuma, M.D.

Department of Human Pathology

Kanazawa University Graduate School of Medicine

Kanazawa 920-8640, Japan

FAX : (0)76-234-4229 (Japan)

TEL : (0)76-265-2195 (Japan)

e-mail : pbcpsc@kenroku.kanazawa-u.ac.jp 


\begin{abstract}
Biliary epithelial cells possess an innate immune system consisting of Toll-like receptors (TLRs). Although human bile contains LPS in normal as well as diseased livers, lipopolysaccharide (LPS) physiologically does not elicit an inflammatory response in the biliary tree. This absence of a response to LPS could be due to the "endotoxin tolerance" speculated to maintain innate immune homeostasis in organs. Our aim here is to clarify the presence and molecular mechanisms of endotoxin tolerance of biliary epithelium. In nuclear factor- $\kappa \mathrm{B}(\mathrm{NF}-\kappa \mathrm{B})$-DNA binding assays using three cultured human intrahepatic biliary epithelial cell (HIBEC) lines, all the cells responded to LPS (TLR4 ligand) by activating $\mathrm{NF}-\kappa \mathrm{B}$, but pretreatment with LPS for $24 \mathrm{~h}$ effectively induced tolerance against any subsequent stimulation with LPS (endotoxin tolerance). This tolerance was also induced by pretreatment with $\mathrm{Pam}_{3}$ Cys-Ser-(Lys) 4 trihydrochloride ( $\mathrm{Pam}_{3} \mathrm{CKS}_{4}, \mathrm{TLR} 1 / 2$ ligand). Then, real-time PCR and Western blotting revealed that LPS- treatment up-regulated the expression of IRAK-M (a negative regulator of TLR signaling), but did not affect IL-1 receptor-associated kinase-1 (IRAK-1, an essential molecule of TLR signaling), in HIBECs. Moreover, immunohistochemistry revealed that IRAK-M was diffusely expressed in intrahepatic bile ducts. This study showed that the mechanism of endotoxin tolerance exist in the intrahepatic biliary tree and possibly is induced by the expression of IRAK-M in intrahepatic biliary epithelium, suggesting that the endotoxin tolerance is important in maintaining innate immune biliary homeostasis.
\end{abstract}

Key Words: biliary epithelial cells, endotoxin tolerance, innate immunity, Toll-like receptor, IRAK 


\section{INTRODUCTION}

The intrahepatic biliary tree is anatomically connected to the duodenum. Human bile contains microbial products termed pathogen-associated molecular patterns (PAMPs) which might be secreted from hepatocytes which take up PAMPs from portal blood inflowing in the gastrointestinal tract and infrequently might be derived from the duodenum (1-5). Therefore, the luminal surface of the intrahepatic bile duct is continually exposed to PAMPs via bile and/or portal blood. We have recently shown that biliary epithelial cells possess essential components of the innate immune system including Toll-like receptors (TLRs) which recognize PAMPs in normal or diseased livers (5). Physiologically, however, PAMPs do not elicit an inflammatory response in biliary lining epithelial cells of intrahepatic bile ducts. This failure to respond to PAMPs, especially lipopolysaccharide (LPS), could be due to "endotoxin tolerance." This tolerance can be considered a protective mechanism that prevents damage to the body by avoiding excessive inflammation, for instance, in sepsis patients and also that attenuates the immune response of intestinal epithelium against the resident intestinal bacterial flora under physiologic conditions. The phenomenon and molecular mechanisms of endotoxin tolerance have been investigated extensively in immunocytes such as monocytes/macrophages (6-9) and also in organs such as the intestines which contain intestinal bacterial flora (10). However, no such studies have been done in the intrahepatic biliary tree.

TLR interacts with an adaptor protein, myeloid differentiation factor 88 (MyD88), which recruits IL-1 receptor-associated kinase (IRAK) $(11,12)$. To date, four different IRAK-like molecules have been identified: two active kinases, IRAK-1 and IRAK-4, and two inactive kinases, IRAK-2 and IRAK-M. IRAK becomes activated in association with tumor necrosis factor (TNF) receptor-associated factor 6 (TRAF6), leading to the activation of several 
distinct signaling pathways, including nuclear factor- $\kappa \mathrm{B}(\mathrm{NF}-\kappa \mathrm{B})$ and mitogen activated protein kinase (MAPK) (13). Among the four IRAKs, IRAK-M negatively regulates TLR signaling by inhibiting the activation of IRAK-1 and MyD88 (14). LPS-tolerant cells exhibit a significantly suppressed LPS-induced activation and degradation of IRAK-1 and diminished IRAK-1-MyD88 association (15) (Fig.1). In addition, as a negative regulator, Toll-interacting protein (Tollip) functions through its ability to potently suppress the activity of IRAK after the activation of TLRs $(10,16)$ (Fig.1). These results imply that the induction of tolerance may affect the expression and/or functions of intracellular intermediates downstream of TLRs.

We hypothesized that endotoxin tolerance in the intrahepatic biliary tree is important to maintaining innate immune biliary homeostasis and possibly associated with the pathogenesis of biliary diseases. In this study, we tried to clarify if and how tolerance is induced by LPS in the human intrahepatic biliary epithelium by using cultured biliary epithelial cells and human liver tissues. 


\section{MATERIALS AND METHODS}

\section{PAMPs and Antibodies}

LPS (Ultra pure, purified from E.coli strain 0111:B4, TLR4 ligand) and $\mathrm{Pam}_{3}$ Cys-Ser-(Lys) $)_{4}$ trihydrochloride $\left(\mathrm{Pam}_{3} \mathrm{CSK}_{4}\right.$, synthetic cationic lipohexapeptide analog, TLR1/2 ligand) were purchased from InvivoGen (San Diego, CA, USA). Antibodies specific for human TLR4 and IRAK-1 (rabbit IgG, polyclonal, Santa Cruz Biotechnology, Santa Cruz, CA, USA), and human IRAK-M (rabbit IgG, polyclonal, Chemicon, Temecula, CA, USA) were used for Western blotting and immunohistochemistry.

\section{Isolation of Biliary Epithelial Cells and Cell Culture}

A fresh liver specimen was mechanically diced and enzymatically digested with collagenase, and then biliary epithelial cells were immunomagnetically separated from the digested cells using CD326 (EpCAM) MicroBeads (Miltenyi Biotec K.K., Tokyo, Japan) $(17,18)$. Three kinds of human intrahepatic biliary epithelial cells (HIBEC1-HIBEC3) were used between passages 4 and 6 in this study. These were lines of cultured cells established from background liver tissue showing a normal histology remote from metastatic foci in surgically resected liver with metastatic tumors. These cells were grown as monolayers in a standard medium containing fetal calf serum (Invitrogen, Tokyo, Japan) in a 5\% $\mathrm{CO}_{2}$-humidified incubator at $37^{\circ} \mathrm{C}$. The cell lines had been confirmed to be biliary epithelial cells by the expression of a biliary-type cytokeratin (CK19) and a marker of polarity (cystic fibrosis transmembrane conductance regulator, CFTR). These cells were stimulated with LPS $(1 \mu \mathrm{g} / \mathrm{mL})$ for $2 \mathrm{~h}, 3 \mathrm{~h}$ or $24 \mathrm{~h}$ at $37^{\circ} \mathrm{C}$ and then used for the preparation of samples for the $\mathrm{NF}-\kappa \mathrm{B}$ assay, polymerase chain reaction (PCR), and Western blotting, respectively, as shown below. 


\section{Real-time PCR}

Quantitative PCR was used for the measurements of TNF- $\alpha$, IRAK-1, IRAK-M, and Tollip mRNAs. Total RNA was isolated using the RNeasy Total RNA System (Qiagen, Hilden, Germany) following the manufacturer's instructions. For synthesizing a cDNA template for PCR, total RNA was reverse transcribed with an oligo-d(T) primer and reverse transcriptase. Real-time PCR was performed for quantitative analyses according to the standard protocol using the SYBR Green PCR Master Mix and ABI PRISM 7700 Sequence Detection System (Applied Biosystems, Tokyo, Japan). Specific primers for TNF- $\alpha$, IRAK-1, IRAK-M, and glyceraldehyde 3 phosphate dehydrogenase (GAPDH, positive control) were designed to meet specific criteria using Primer Express Software (Applied Biosystems).

\section{Western blotting}

Cultured cells were homogenized in protein extraction reagent (Pierce, Rockford, IL, USA) with protease inhibitors and then centrifuged. Supernatants were separated by sodium

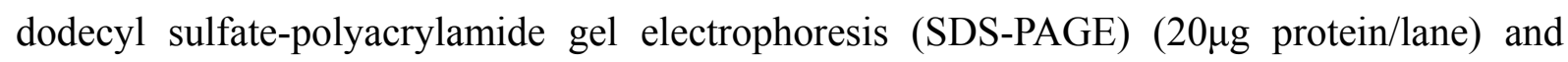
electrically transferred to a nitrocellulose membrane. The membrane was blocked with $1 \%$ bovine serum albumin, and then incubated with antibodies specific for human IRAK-1, IRAK-M, and TLR4 $(0.5 \mu \mathrm{g} / \mathrm{ml})$. Reactive bands were visualized with anti-mouse or anti-rabbit immunoglobulin conjugated to a peroxidase-labeled dextran polymer (Envision ${ }^{\mathrm{TM}}$, Dako, Tokyo, Japan) and a benzidine reaction.

\section{NF-кB DNA-binding assay}

$\mathrm{NF}-\kappa \mathrm{B}$ activity was measured based on the DNA-binding capacity of NF- $\mathrm{B}$ using a $\operatorname{Trans}^{\mathrm{AM}}{ }^{\mathrm{TM}} \mathrm{NF}-\kappa \mathrm{B}$ Kit (Active Motif, Carlsbad, CA, USA) $(5,19)$. Briefly, nuclear extracts

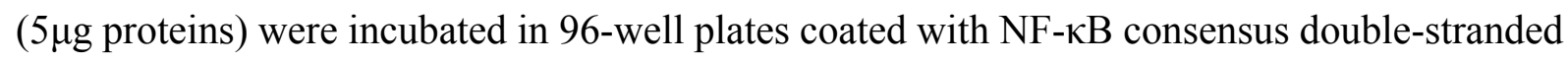


oligonucleotide (5'-AGTTGAGGGGACTTTCCCAGGC-3') and then with the supplied primary anti-NF- $\mathrm{B}$ antibody and subsequently with a secondary peroxidase-conjugated antibody. After a colorimetric reaction, the optical density was read at $450 \mathrm{~nm}$. Competition experiments were conducted with the 22bp double-stranded DNA, either wild-type (see above) or mutated: 5'-AGTTGAGCTCACTTTCCCAGGC (with three mutated bases underlined).

\section{Preparation of human liver tissue and immunohistochemistry}

All tissue specimens were collected from the hepatobiliary file of our department. Informed consent to conduct research was obtained from all patients. This study was approved by the Kanazawa University Ethics Committee.

Formalin-fixed specimens: A total of 8 surgical liver specimens were obtained from patients with a histologically "normal liver" (mean age 72yr, male/female=5/3). These specimens were obtained from non-neoplastic parts of livers surgically resected for a metastatic tumor. All were neutral formalin-fixed paraffin-embedded tissues; $4 \mu \mathrm{m}$-thick sections were prepared for routine histologic observation and immunohistochemistry.

Immunohistochemistry: Deparaffinized sections heat-treated in citrate buffer were incubated overnight with antibodies against human IRAK-M $(1 \mu \mathrm{g} / \mathrm{ml})$, and then with the ENVISON system for $1 \mathrm{~h}$. After a benzidine reaction, sections were counterstained with hematoxylin. As a negative control, normal rabbit $\operatorname{IgG}(1 \mu \mathrm{g} / \mathrm{ml})$ was used for the primary antibody; this always resulted in negative staining.

\section{Statistical analysis}

Data were analyzed using the paired t-test and $\mathrm{p}<0.05$ was considered statistically significant. 


\section{RESULTS}

\section{$N F-\kappa B$ activation and TNF- $\alpha$ mRNA production on treatment with LPS and $\mathrm{Pam}_{3} \mathrm{CSK}_{4}$}

HIBECs were stimulated with LPS $(1 \mu \mathrm{g} / \mathrm{ml})$ and $\mathrm{Pam}_{3} \mathrm{CSK}_{4}(300 \mathrm{ng} / \mathrm{ml})$ and the activation of NF- $\kappa \mathrm{B}$ and production of TNF- $\alpha$ mRNA were measured by conducting a NF- $\mathrm{B}$ DNA-binding assay and quantitative analysis using real-time PCR, respectively. A small amount of NF- $\mathrm{kB}$ was observed in cells without any stimulation, while significant upregulation of NF- $\mathrm{BB}$ activity was obtained on stimulation with LPS and $\mathrm{Pam}_{3} \mathrm{CSK}_{4}$. As shown in Fig.2,

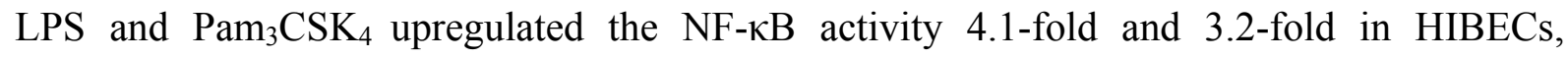
respectively, when compared to untreated cells. In addition, TNF- $\alpha$ mRNA expression in HIBECs was also upregulated by LPS and $\mathrm{Pam}_{3} \mathrm{CSK}_{4}, 294$-fold and 229-fold, respectively. Furthermore, as shown in Fig.3, the TNF- $\alpha$ mRNA expression induced by LPS and $\mathrm{Pam}_{3} \mathrm{CSK}_{4}$ was markedly and gradually reduced on and after $6 \mathrm{~h}$.

\section{Endotoxin Tolerance induced by pretreatment with LPS and $\mathrm{Pam}_{3} \mathrm{CSK}_{4}$}

We first examined the ability of LPS to induce tolerance to innate immunity. HIBECs were pretreated with LPS $(1 \mu \mathrm{g} / \mathrm{ml})$ for $24 \mathrm{~h}$. Pretreated cells were washed and replaced with new standard medium and subjected to another LPS challenge. The NF- $\kappa$ B activity and TNF- $\alpha$ mRNA levels were subsequently assayed. Consequently, HIBECs pretreated with LPS developed tolerance to a subsequent LPS challenge (homo-tolerance): the degree of LPS-induced NF- $\kappa$ B activity was significantly decreased from 4.1-fold (first LPS challenge) to 1.6-fold (subsequent LPS challenge) and the TNF- $\alpha$ mRNA level was also significantly decreased from 294-fold (first LPS challenge) to 6.5-fold (subsequent LPS challenge), compared with no stimulants (Fig.2).

Next, HIBEC cells were pretreated with $\mathrm{Pam}_{3} \mathrm{CSK}_{4}(300 \mathrm{ng} / \mathrm{ml})$ for $24 \mathrm{~h}$ and subjected to another LPS challenge. Pretreatment with $\mathrm{Pam}_{3} \mathrm{CSK}_{4}$ also significantly decreased both NF-kB 
activity (2.8-fold) and the TNF- $\alpha$ mRNA level (11.0-fold) in response to a subsequent LPS challenge (cross-tolerance) (Fig.2).

\section{Expression of IRAK-1, IRAK-M, Tollip, and TLR4 in HIBECs}

The mRNA expression of negative regulators of TLR intracellular signaling, IRAK-M and Tollip, and their changes on the treatment with LPS $(1 \mu \mathrm{g} / \mathrm{ml})$ and $\mathrm{Pam}_{3} \mathrm{CSK}_{4}(300 \mathrm{ng} / \mathrm{ml})$, were examined. Baseline levels of both IRAK-M and Tollip mRNAs were detected without any stimulation by PCR. However, real-time PCR revealed that IRAK-M expression was significantly increased by the treatment with LPS and $\mathrm{Pam}_{3} \mathrm{CSK}_{4}$ for $3 \mathrm{~h}$, but that Tollip expression was not affected by any treatment (Fig.4). In addition to the mRNA level, the IRAK-M protein level was also examined by Western blot analysis. As shown in Fig.5, a faint band corresponding to IRAK-M was observed in unstimulated (non-tolerant) HIBECs and the expression of IRAK-M was confirmed to be significantly upregulated in the cells treated with LPS or $\mathrm{Pam}_{3} \mathrm{CSK}_{4}$ at 24h post-stimulation (LPS-tolerant cells).

Previous studies reported that IRAK-1 (essential for TLR intracellular signaling) and TLR4 (LPS receptor) are down-regulation in LPS-tolerant cells $(9,10,20,21)$. To verify these mechanisms of endotoxin tolerance in HIBECs, the expressions of IRAK-1 and TLR4 were examined in LPS-tolerant HIBEC cells. As shown in Fig.4 and Fig.5, IRAK-1 mRNA and protein were constitutively expressed in unstimulated (non-tolerant) HIBECs and there was no significant difference in mRNA and protein levels with and without LPS or $\mathrm{Pam}_{3} \mathrm{CSK}_{4}$ treatments. TLR4 protein was also constitutively expressed in unstimulated (non-tolerant) HIBECs, and was not decreased, rather slightly increased in HIBEC1, by neither LPS nor $\mathrm{Pam}_{3} \mathrm{CSK}_{4}$ treatment (Fig.5).

\section{Expression of IRAK-M in human intrahepatic bile ducts}


By immunohistochemistry, IRAK-M was mostly detected in the cytoplasm of biliary epithelial cells of the intrahepatic large bile ducts, septal bile ducts, and interlobular bile ducts, and also bile ductules (Fig.6) (22). The expression pattern in biliary epithelial cells was similar at the different levels of the intrahepatic bile ducts. In addition, IRAK-M was diffusely expressed in the cytoplasm of hepatocytes and in the nucleus of several hepatocytes and in the cytoplasm of several infiltrating mononuclear cells and endothelial cells. 


\section{DISCUSSION}

LPS, the major structural component of the outer wall of Gram-negative bacteria, is a potent activator of the immune system. The recognition of LPS is predominantly mediated by TLR4 $(12,23,24)$, and involves the binding of LPS with a LPS-binding protein which physically associates with a complex comprising TLR4 and the TLR4 accessory molecule MD2. We have previously demonstrated that biliary epithelial cells express TLR4 and MD2 $(5,25,26)$. Moreover, under serum-free conditions, LPS-induced NF- $\kappa \mathrm{B}$ activation was markedly reduced in HIBECs, because serum contains LPS-binding protein, suggesting that biliary epithelial cells also require LPS-binding protein for the recognition of LPS through TLR4 (26). The activation of TLRs subsequently leads to common downstream signaling events, including the activation of MyD88/IRAK kinase, MAPKs and NF- $\kappa \mathrm{B}$, which contribute to the production of (pro)inflammatory cytokines and peptide antibiotics. Our previous study demonstrated that biliary epithelial cells produce a peptide antibiotic, human beta-defensin 2, in response to LPS via the activation of TLR4 and NF-kB (17).

Large quantities of LPS are known to induce the overproduction of cytokines causing septic shock while suboptimal doses could induce tolerance to subsequent exposure to LPS (27). This endotoxin tolerance is an important mechanism to maintain the homeostasis of intestinal epithelial cells which constitutively face commensal flora (10). Although human bile contains LPS in normal as well as diseased livers, biliary epithelial cells are thought to possess a similar mechanism of tolerance to that seen in the intestine, because intrahepatic biliary epithelium is continually exposed to various PAMPs including LPS in bile $(2,3,5)$, but PAMPs do not elicit an inflammatory response in biliary epithelial cells in vivo. In present study, we found that pretreatment with LPS for $24 \mathrm{~h}$ significantly induced tolerance to a subsequent challenge as assessed by the activation of NF- $\kappa \mathrm{B}$ and production of TNF- $\alpha$ mRNA 
in HIBECs, demonstrating the presence of endotoxin tolerance in biliary epithelial cells.

Among all forms of PAMP-induced tolerance, LPS-mediated homo-tolerance has been most extensively studied, but molecular mechanisms of TLR4-mediated tolerance have not been fully clarified. Recent studies have found that IRAK-M plays a critical negative regulatory role in signaling via TLRs in monocytes/macrophages (14). IRAK-M ${ }^{-/}$ macrophages stimulated with LPS displayed increased NF- $\kappa \mathrm{B}$ and MAPK activation, compared with IRAK-M ${ }^{+/+}$macrophages and endotoxin tolerance was significantly attenuated in IRAK-M ${ }^{-/-}$cells (14). It is well established that after the treatment with LPS, the structural complex formed by MyD88, IRAK-1, IRAK-4, and TRAF-6 induces a series of phosphorylation events that conclude with the activation of two mediators central to the immune response, NF- $\mathrm{KB}$ and AP-1 (28). It has been suggested that IRAK-M might block the aforementioned signaling pathways, especially the signaling between MyD88 and IRAK-1, by binding to the complex $(14,28)$. In the present study, we showed that IRAK-M protein was faintly detectable in untreated HIBECs and the expression of IRAK-M mRNA and its protein was up-regulated in LPS-treated HIBECs, implying that the induction of IRAK-M interferes with the association between IRAK-1 and MyD88 and is crucial to LPS-induced endotoxin tolerance in biliary epithelial cells. Furthermore, using human liver tissue sections showing normal histology, we confirmed that IRAK-M is expressed in vivo. Consequently, IRAK-M was constitutively expressed in the cytoplasm of biliary epithelial cells, irrespective of intrahepatic biliary levels. This finding suggests that the expression of IRAK-M is associated with a decrease or loss of responsiveness to PAMPs in bile and/or portal flow. In addition, immunohistochemistry revealed that hepatocytes also constitutively express IRAK-M. Hepatocytes physiologically face to PAMPs originated from intestinal bacterial flora via portal blood. In this study, we could not confirm the presence of endotoxin tolerance in 
hepatocytes, but hepatocytes also possess IRAK-M-associated tolerance systems similar to those of biliary epithelial cells.

Induction of endotoxin-tolerance is not specific for the initiating action of LPS, because engagement with TLR/IL-1 receptor (IL-1R) family members other than TLR4, also results in resistance to a subsequent challenge with the respective ligands (29). We demonstrated that pretreatment with $\mathrm{Pam}_{3} \mathrm{CSK}_{4}$ (TLR1/2 ligand) for $24 \mathrm{~h}$ also could effectively induce tolerance to further stimulation with LPS (TLR4 ligand). This cross-tolerance against LPS (TLR4 ligand) by PAMPs recognized by TLR2 such as peptidoglycan and lipoteichoic acid was already demonstrated in monocytes and intestinal epithelial cells $(9,10,29)$. The present study revealed that $\mathrm{Pam}_{3} \mathrm{CSK}_{4}$ as well as LPS could induce IRAK-M expression in HIBECs. This finding suggests that endotoxin tolerance caused by an up-regulation of IRAK-M expression is also associated with cross-tolerance to LPS induced by $\mathrm{Pam}_{3} \mathrm{CSK}_{4}$.

As other mechanisms of endotoxin tolerance, involvement of the down-regulation of TLR4 expression $(10,21)$ and degradation of IRAK-1 has been reported $(9,10,20)$. To test these possibilities, we examined the expression of IRAK-1 and TLR4 in LPS-tolerant HIBECs. IRAK-1 mRNA expression was not altered in response to LPS or $\mathrm{Pam}_{3} \mathrm{CSK}_{4}$ and levels of IRAK-1 and TLR4 proteins were well-conserved. This finding suggests that the degradation of IRAK-1 and TLR4 protein would be unlikely in LPS-tolerant HIBECs. Moreover, Tollip has been reported as a suppressor molecule in TLR intracellular signaling $(10,16,30)$. Various intestinal epithelial cells constitutively or inducibly express a large amount of Tollip (10,31). The inhibition of TLR signaling by Tollip appears to be mediated through an ability to suppress the activity of IRAK after the activation of TLR2 and TLR4. Biliary epithelial cells as well as intestinal epithelial cells were also demonstrated to express Tollip mRNA in this study. However, a distinct up-regulation of Tollip mRNA expression was 
not found in response to LPS nor $\mathrm{Pam}_{3} \mathrm{CSK}_{4}$ in HIBECs, indicating that Tollip is not associated with the molecular mechanism underlying LPS-tolerance in biliary epithelial cells.

In conclusion, this study demonstrated endotoxin tolerance in the intrahepatic biliary epithelium and suggests that the expression of IRAK-M is crucial to LPS-induced tolerance in biliary epithelial cells. It is speculated that endotoxin tolerance is important in maintaining innate immune biliary homeostasis and also that an impaired tolerance to LPS is associated with the pathogenesis of biliary diseases. 


\section{REFERENCES}

1. Sheen-Chen S, Chen W, Eng $\mathrm{H}$, et al. Bacteriology and antimicrobial choice in hepatolithiasis. Am J Infect Control 2000; 28: 298-301.

2. Hiramatsu K, Harada K, Tsuneyama K, et al. Amplification and sequence analysis of partial bacterial $16 \mathrm{~S}$ ribosomal RNA gene in gallbladder bile from patients with primary biliary cirrhosis. J Hepatol 2000; 33: 9-18.

3. Osnes T, Sandstad O, Skar V, Osnes M. Lipopolysaccharides and beta-glucuronidase activity in choledochal bile in relation to choledocholithiasis. Digestion 1997; 58: 437-443.

4. Sasatomi K, Noguchi K, Sakisaka S, Sata M, Tanikawa K. Abnormal accumulation of endotoxin in biliary epithelial cells in primary biliary cirrhosis and primary sclerosing cholangitis. J Hepatol 1998; 29: 409-416.

5. Harada K, Ohira S, Isse K, et al. Lipopolysaccharide activates nuclear factor-kappaB through toll-like receptors and related molecules in cultured biliary epithelial cells. Lab Invest 2003; 83: 1657-1667.

6. Medvedev AE, Lentschat A, Wahl LM, Golenbock DT, Vogel SN. Dysregulation of LPS-induced Toll-like receptor 4-MyD88 complex formation and IL-1 receptor-associated kinase 1 activation in endotoxin-tolerant cells. J Immunol 2002; 169: 5209-5216.

7. Nakayama K, Okugawa S, Yanagimoto $S$, et al. Involvement of IRAK-M in peptidoglycan-induced tolerance in macrophages. J Biol Chem 2004; 279: 6629-6634.

8. Escoll P, del Fresno C, Garcia L, et al. Rapid up-regulation of IRAK-M expression following a second endotoxin challenge in human monocytes and in monocytes isolated from septic patients. Biochem Biophys Res Commun 2003; 311: 465-472.

9. Jacinto R, Hartung T, McCall C, Li L. Lipopolysaccharide- and lipoteichoic acid-induced tolerance and cross-tolerance: distinct alterations in IL-1 receptor-associated kinase. J Immunol 2002; 168: 6136-6141.

10. Otte JM, Cario E, Podolsky DK. Mechanisms of cross hyporesponsiveness to Toll-like receptor bacterial ligands in intestinal epithelial cells. Gastroenterology 2004; 126: 1054-1070.

11. Takeuchi O, Hoshino K, Kawai $\mathrm{T}$, et al. Differential roles of TLR2 and TLR4 in recognition of gram-negative and gram-positive bacterial cell wall components. Immunity 1999; 11: 443-451.

12. Kaisho T, Akira S. Toll-like receptors as adjuvant receptors. Biochim Biophys Acta 2002; 1589: 1-13.

13. Takeda K, Akira S. Toll-like receptors in innate immunity. Int Immunol 2005; 17: 1-14. 
14. Kobayashi K, Hernandez LD, Galan JE, et al. IRAK-M is a negative regulator of Toll-like receptor signaling. Cell 2002; 110: 191-202.

15. Li L, Cousart S, Hu J, McCall CE. Characterization of interleukin-1 receptor-associated kinase in normal and endotoxin-tolerant cells. J Biol Chem 2000; 275: 23340-23345.

16. Zhang G, Ghosh S. Negative regulation of toll-like receptor-mediated signaling by Tollip. J Biol Chem 2002; 277: 7059-7065.

17. Harada K, Ohba K, Ozaki S, et al. Peptide antibiotic human beta-defensin-1 and -2 contribute to antimicrobial defense of the intrahepatic biliary tree. Hepatology 2004; 40: 925-932.

18. Kamihira T, Shimoda S, Harada $\mathrm{K}$, et al. Distinct costimulation dependent and independent autoreactive T-cell clones in primary biliary cirrhosis. Gastroenterology 2003; 125: 1379-1387.

19. Renard P, Ernest I, Houbion A, et al. Development of a sensitive multi-well colorimetric assay for active NFkappaB. Nucleic Acids Res 2001; 29: E21.

20. Siedlar M, Frankenberger M, Benkhart E, et al. Tolerance induced by the lipopeptide Pam3Cys is due to ablation of IL-1R-associated kinase-1. J Immunol 2004; 173: 2736-2745.

21. Nomura F, Akashi S, Sakao Y, et al. Cutting edge: endotoxin tolerance in mouse peritoneal macrophages correlates with down-regulation of surface toll-like receptor 4 expression. J Immunol 2000; 164: 3476-3479.

22. Nakanuma Y, Hoso M, Sanzen T, Sasaki M. Microstructure and development of the normal and pathologic biliary tract in humans, including blood supply. Microsc Res Tech 1997; 38: 552-570.

23. Chow JC, Young DW, Golenbock DT, Christ WJ, Gusovsky F. Toll-like receptor-4 mediates lipopolysaccharide-induced signal transduction. J Biol Chem 1999; 274: 10689-10692.

24. Jiang Q, Akashi S, Miyake K, Petty HR. Lipopolysaccharide induces physical proximity between CD14 and toll-like receptor 4 (TLR4) prior to nuclear translocation of NF-kappa B. J Immunol 2000; 165: 3541-3544.

25. Harada K, Isse K, Kamihira T, Shimoda S, Nakanuma Y. Th1 cytokine-induced downregulation of PPARgamma in human biliary cells relates to cholangitis in primary biliary cirrhosis. Hepatology 2005; 41: 1329-1338.

26. Harada K, Isse K, Nakanuma Y. Interferon gamma accelerates NF-kappaB activation of biliary epithelial cells induced by Toll-like receptor and ligand interaction. J Clin Pathol 2006; 59: 184-190.

27. Fujihara M, Muroi M, Tanamoto K, et al. Molecular mechanisms of macrophage 
activation and deactivation by lipopolysaccharide: roles of the receptor complex. Pharmacol Ther 2003; 100: 171-194.

28. Janssens S, Beyaert R. Functional diversity and regulation of different interleukin-1 receptor-associated kinase (IRAK) family members. Mol Cell 2003; 11: 293-302.

29. Lehner MD, Morath S, Michelsen KS, Schumann RR, Hartung T. Induction of cross-tolerance by lipopolysaccharide and highly purified lipoteichoic acid via different Toll-like receptors independent of paracrine mediators. J Immunol 2001; 166: 5161-5167.

30. Burns K, Clatworthy J, Martin L, et al. Tollip, a new component of the IL-1RI pathway, links IRAK to the IL-1 receptor. Nat Cell Biol 2000; 2: 346-351.

31. Melmed G, Thomas LS, Lee N, et al. Human intestinal epithelial cells are broadly unresponsive to Toll-like receptor 2-dependent bacterial ligands: implications for host-microbial interactions in the gut. J Immunol 2003; 170: 1406-1415. 


\section{FIGURE LEGENDS}

Fig.1 A schema for signaling pathway consisting of Toll-like receptors (TLRs), their ligands, and signaling molecules. IL-1 receptor-associated kinase-M (IRAK-M) and Toll-interacting protein (Tollip) act as negative regulators of intracellular signaling pathways. LPS, lipopolysaccharide; $\quad \mathrm{Pam}_{3} \mathrm{CKS}_{4}, \quad \mathrm{Pam}_{3}$ Cys-Ser-(Lys) trihydrochloride; MyD88, myeloid differentiation factor 88; TRAF6, tumor necrosis factor receptor-associated factor 6 ; NF- $\kappa \mathrm{B}$, nuclear factor- $\kappa \mathrm{B}$.

Fig.2 NF- $\kappa$ B activation (A) and TNF- $\alpha$ mRNA production (B) induced by treatments with LPS and $\mathrm{Pam}_{3} \mathrm{CSK}_{4}$ and endotoxin tolerance induced by pretreatment with LPS and

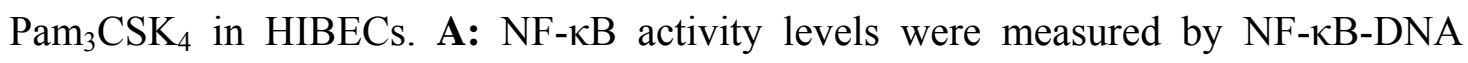
binding assay and the $y$-axis shows a relative increase compared with unstimulated samples. NF- $\kappa$ B activity in HIBECs was increased $4.1 \pm 0.4$-fold (mean \pm S.E.M) by LPS $(1 \mu \mathrm{g} / \mathrm{ml})$ and $3.2 \pm 0.7$-fold by $\mathrm{Pam}_{3} \mathrm{CSK}_{4}$ (300ng/ml). This DNA-NF- $\mathrm{BB}$ binding activity was effectively competed for by the wild-type consensus oligonucleotide, but not a mutated oligonucleotide (data not shown). Next, HIBECs were pretreated with LPS or $\mathrm{Pam}_{3} \mathrm{CSK}_{4}$ for $24 \mathrm{~h}$ and subjected to another LPS challenge. Pretreatment with LPS and $\mathrm{Pam}_{3} \mathrm{CSK}_{4}$ significantly decreased NF- $\mathrm{KB}$ activity $1.6 \pm 0.3$-fold and 2.8 \pm 0.4 -fold, respectively, in response to a subsequent LPS challenge. B: Quantitative analysis of TNF- $\alpha$ mRNA production using real-time PCR. The quantification data were normalized to the expression of the housekeeping gene GAPDH and the $y$-axis shows an increase in specific mRNA over unstimulated samples. TNF- $\alpha$ mRNA expression in HIBECs was upregulated by the treatment with LPS and $\mathrm{Pam}_{3} \mathrm{CSK}_{4}$ $294 \pm 89$-fold and $229 \pm 77$-fold, respectively, compared with no stimulants. The degree 
of LPS-induced TNF- $\alpha$ mRNA production was significantly decreased $6.5 \pm 3.8$-fold and 11.0 \pm 2.6 -fold by the pretreatment with LPS and $\mathrm{Pam}_{3} \mathrm{CSK}_{4}$, respectively. Data represent the mean \pm S.E.M from duplicate experiments using HIBEC1-HIBEC3. $*<0.05$.

Fig.3 TNF- $\alpha$ mRNA production induced by treatment with LPS $(1 \mu \mathrm{g} / \mathrm{ml})$ or $\mathrm{Pam}_{3} \mathrm{CSK}_{4}$ (300ng/ml) for the period indicated. TNF- $\alpha$ mRNA was measured at $3,6,12$, and $24 \mathrm{~h}$ after the treatment by using real-time PCR. The quantification data were normalized to the expression of the housekeeping gene GAPDH and the $y$-axis shows an increase in specific mRNA over unstimulated samples. The relative increase of TNF- $\alpha$ mRNA expression caused by LPS and $\mathrm{Pam}_{3} \mathrm{CSK}_{4}$ treatment was 326.2 and 253.2 at 3h, 98.7 and 21.5 at $6 \mathrm{~h}, 15.7$ and 6.5 at $12 \mathrm{~h}$, and 1.1 and 1.5 at $24 \mathrm{~h}$, respectively. Values are the average of data obtained using HIBEC1-HIBEC3.

Fig. 4 Quantitative analysis of the expression of IRAK-1, IRAK-M and Tollip mRNAs induced by treatment with LPS and $\mathrm{Pam}_{3} \mathrm{CSK}_{4}$ in HIBECs. The data obtained real-time PCR were normalized to the expression of the housekeeping gene GAPDH and the $y$-axis shows an increase in specific mRNA over unstimulated samples. IRAK-M mRNA expression in HIBECs was upregulated 3.4 \pm 0.5 -fold (mean \pm S.E.M) and 3.1 \pm 0.6 -fold by treatment with LPS $(1 \mu \mathrm{g} / \mathrm{ml})$ and $\mathrm{Pam}_{3} \mathrm{CSK}_{4}(300 \mathrm{ng} / \mathrm{ml})$ for $3 \mathrm{~h}$, respectively. The expression levels of IRAK-1 and Tollip mRNAs in HIBECs were not affected by any treatment: the relative increase of IRAK-1 mRNA expression was $1.1 \pm 0.2$ and $1.0 \pm 0.3$ and that of Tollip mRNA was $1.1 \pm 0.3$ and $1.3 \pm 0.2$ on treatment with LPS and $\mathrm{Pam}_{3} \mathrm{CSK}_{4}$, respectively. Data represent the mean \pm S.E.M from duplicate 
experiments using HIBEC1-HIBEC3. *<0.05.

Fig.5 Western blot analysis of IRAK-1, IRAK-M, and TLR4 protein levels. HIBEC1 and HIBEC2 cells were treated with LPS $(1 \mu \mathrm{g} / \mathrm{ml})$ or $\mathrm{Pam}_{3} \mathrm{CSK}_{4}(300 \mathrm{ng} / \mathrm{ml})$ or left in medium alone for $24 \mathrm{~h}$. Total protein was isolated from these cells and the expression of IRAK-1, IRAK-M, and TLR4 proteins was analyzed by Western blotting. IRAK-1 protein was constitutively detected in the cells not treated with stimulant (non), and this expression was not affected by any treatment. IRAK-M protein was also detected in the cells under normal conditions (non), but its expression was significantly upregulated by the treatment with each LPS and $\mathrm{Pam}_{3} \mathrm{CSK}_{4}$. TLR4 protein was also constitutively expressed in the unstimulated HIBECs and no degradation of TLR4 was found, rather, TLR4 levels increased slightly in HIBEC1, on LPS or Pam ${ }_{3} \mathrm{CSK}_{4}$ treatment.

Fig. 6 Immunohistochemistry for IRAK-M (A and C) and a negative control (B and D) using human liver sections showing a normal histology. IRAK-M is mostly expressed in the cytoplasm of biliary epithelial cells of large bile ducts (A, large arrow) and interlobular bile ducts (B, arrow). Hepatocytes also express IRAK-M in their cytoplasm and part of the nucleus (C, arrowheads). Moreover, IRAK-M-positive infiltrating mononuclear cells (A, arrowheads) and endothelial cells (A, small arrows) are also found. (B) and (D) are negative controls using nonimmune rabbit IgG instead of the primary IRAK-M antibody in a serial section adjacent to that shown in (A) and (C), respectively. Specific positive stainings in (A) and (C) is abolished in (B) and (D). 


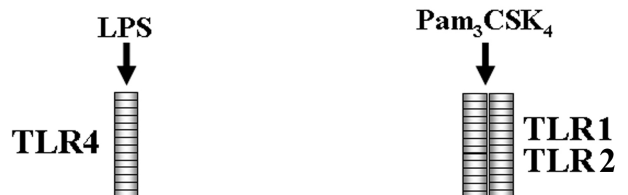

MyD88

IRAK-1/4 Tollip

TRAF6

NF-KB

Fig.1 

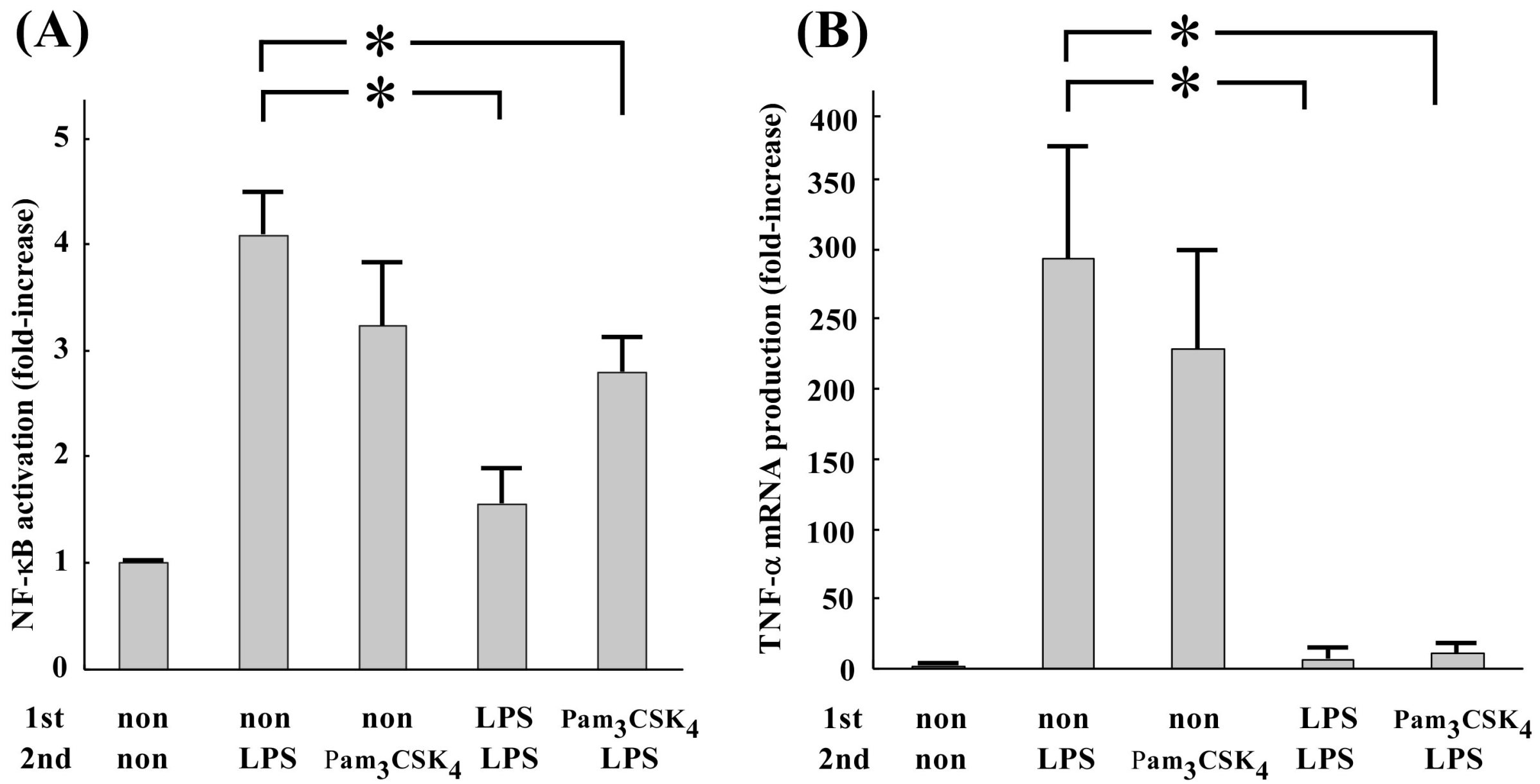

Fig. 2 


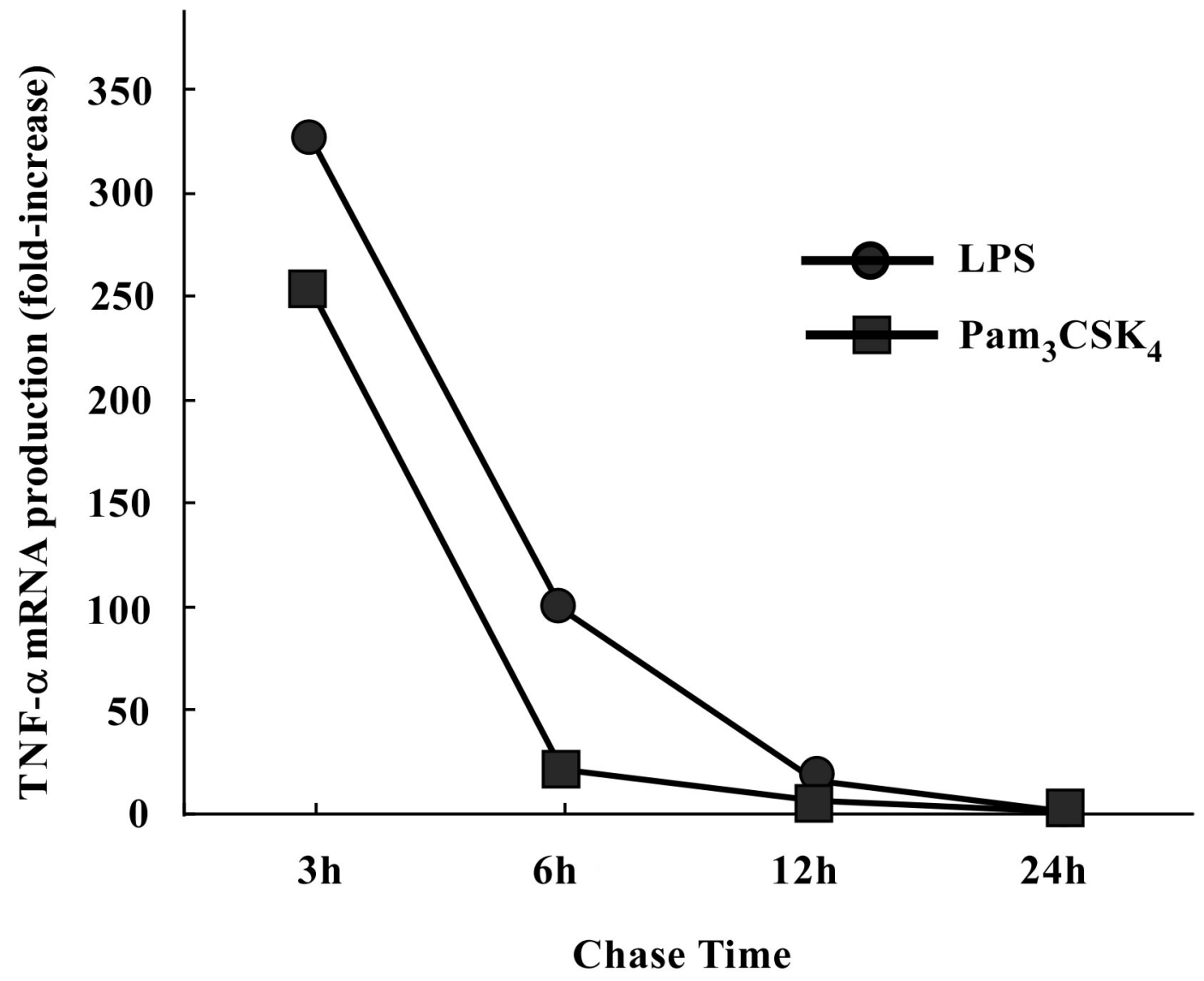

Fig. 3 


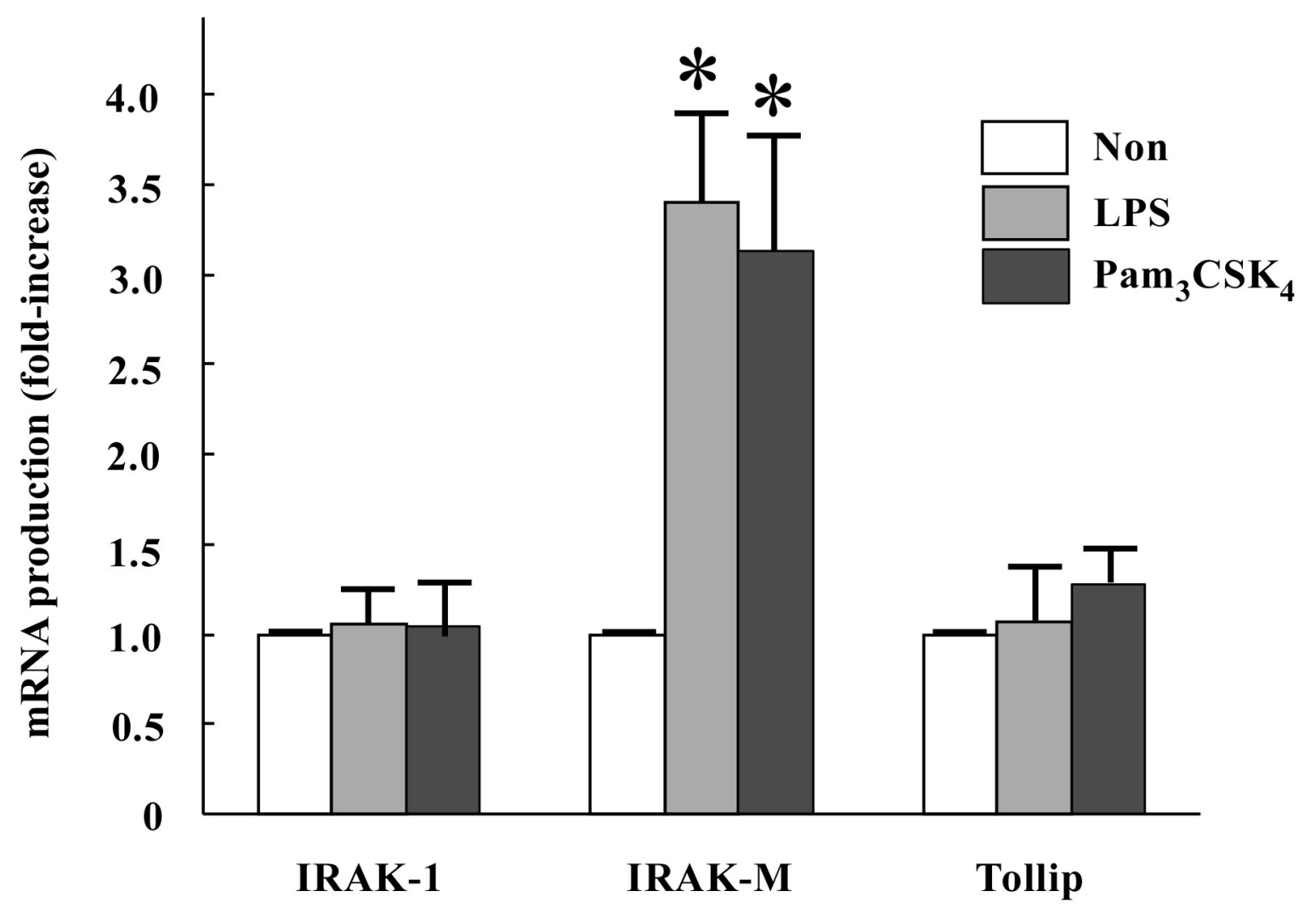

Fig. 4 


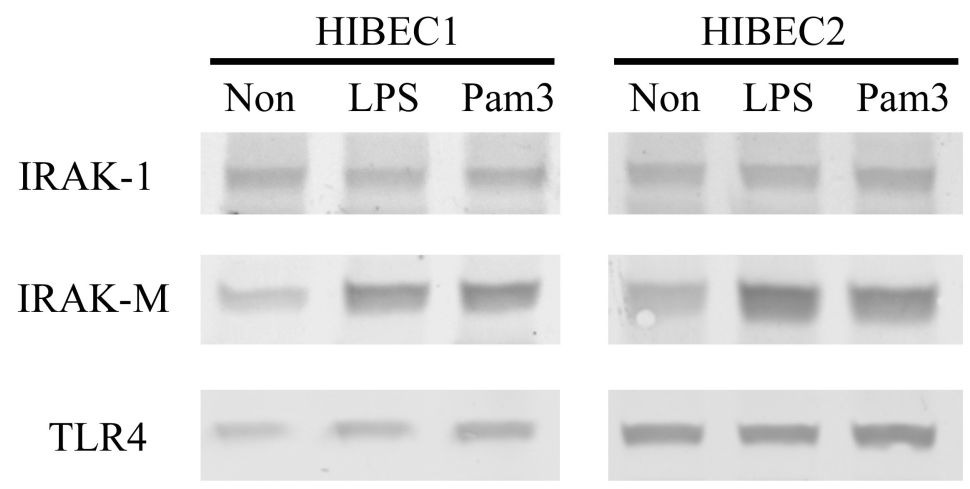

Fig. 5 
